\title{
Role of bilateral internal iliac artery ligation in controlling refractory post partum hemorrhage
}

\author{
Samia Jamil ${ }^{1}$, Sara Munir ${ }^{2}$, Javeria Amin ${ }^{3}$, Shazia Nourin ${ }^{1}$, Alia ${ }^{1}$, Zill e huma ${ }^{4}$, Hamza Saeed \\ Khokhar $^{1}$ *, Sultan UI Moazzam ${ }^{1}$, Muhammad Sohail Afzal ${ }^{5}$ \\ ${ }^{1}$ Department of Gynecology and Obstetrics, King Edward Medical University, Lady Aitchison Hospital, Lahore \\ ${ }^{2}$ Department of Gynecology and Obstetrics, Shaikh Zayed Hospital, Lahore \\ ${ }^{3}$ Department of Gynecology and Obstetrics, Fatima Jinnah Medical University, Government teaching Hospital Shahdara, Lahore \\ ${ }^{4}$ Department of Gynecology and Obstetrics, Amna Inayut Medical College, Lahore \\ ${ }^{5}$ Department of Life Sciences, University of Management and Technology, Lahore \\ *Corresponding author E-mail: hamza.khokhar11413@gmail.com
}

\begin{abstract}
Background: Post Partum Hemorrhage (PPH) is a life threatening emergency that needs to be managed timely. Refractory PPH is treated surgically. Bilateral internal iliac artery ligation is one of the surgical procedures performed to control bleeding.

Objective: We analyzed the effectiveness of Bilateral IIAL in controlling bleeding in PPH

Methodology: It was a retrograde cross-sectional study conducted at Lady Aitchison hospital, Lahore from data during January 2018 to December 2020. After applying inclusion and exclusion criteria, data of patient including demographics, history, examination, ultrasound, procedure details and post-operative complications were recorded. All the data was analyzed using SPSS version 23.0.

Results: All the patients (44) survived and success rate was $100 \%$. Uterine atony was present in $29(65.9 \%)$ patients as a cause of PPH, placental abnormality, uterine rupture and coagulopathy in $7(15,9), 4(9.1 \%)$ and $4(9.1 \%)$ patients respectively. 17 patients did not develop any complication. Most common Post-operative complication was wound infection (22.75\%) followed by pneumonia (20.5\%), paralytic ileus $(9.1 \%)$ and DIC with renal failure $(9.1 \%)$.

Conclusion: Bilateral IIAL was found to be an effective and preferred life saving procedure, preserving fertility.
\end{abstract}

Keywords: Refractory Post Partum Hemorrhage; Internal Iliac Artery Ligation; Post-Operative Complications.

\section{Introduction}

One of the most common obstetric emergencies is postpartum bleeding with the prevalence. Upto $18 \%$ and accounting for $13-34 \%$ of maternal mortality. [1], [2] This variability in mortality depends upon the resources and clinical skills available to the patient. [2] Hemorrhage occurring after delivery is labeled as postpartum hemorrhage (PPH) or postpartum bleeding only if it exceeds $500 \mathrm{ml}$ of blood. ${ }^{2}$ Annually around 20 million women suffer morbidity due to PPH. [3]

The causative agents of this life threatening condition are well studied. Uterine atony is the causative factor in most of the cases of PPH. [4] other notable causes include trauma, retained tissue, placental abnormality and bleeding or coagulation disturbances. [5-8] Although PPH can occur without any risk factor, a greater incidence has been reported in the pregnancies complicated by macrosomia, polyhydramnios and instrumental deliveries. [9], [10]

Postpartum bleeding can lead to anemia, orthostatic hypotension, fatigue, depression, pituitary necrosis, myocardial ischemia, shock and death. [11] Thus, it requires urgent management. Initially it is managed conservatively. Conservative measures commonly employed for therapy include uterine massage, uterotonic agents, anti-fibrinolytics and suturing the bleeding site. [12]

If above-mentioned measures fail, it is labeled as refractory PPH which necessitates. Surgical intervention. A fertility preserving such intervention is Bilateral Internal iliac Artery.

Ligation (IIAL). Its effectiveness is 40-100\%. [13] At one end, it saves fertility but on the other side, carries the risk of re-opening of the abdomen in case hemorrhage doesn't stop. [14] This not only increases the cost of treatment but also affects morbidity. [14], [15] To explore its outcome and complications further, we report a case series in which IIAL was employed to control PPH.

\section{Methodology}

It was a retrograde cross-sectional study conducted at Lady Atichison hospital, Lahore, Pakistan after getting permission from institutional review board. All the cases in which bilateral IIAL was performed by a Consultant Gynecologist having an experience of at least more than 5 years were collected from hospital record from January 2018 to December 2020. All the women who did not respond to possible conservative measures and were requiring hysterectomy for control of bleeding but IAAL was done by a consultant Gynecol- 
ogist, were included in this study. The conservative measures included massage, drugs, removing retained product of conception, applying pressure through tamponade, treating coagulopathy if present and suturing. Whereas those patients who responded to these conservative measures or died during this treatment were excluded from the study.

The data regarding the demography like age, gender etc of all those women who met the inclusion and exclusion criteria was noted. Preoperative assessment made with the help of history, clinical examination and Ultrasound was recorded. The details of procedure, postoperative complications (POC) and outcome in the form of discharge with controlled bleeding or death was also recorded. All this data was collected on a pre-designed Proforma. The collected data was analyzed using SPSS version 23.0. The qualitative measure like gender, POC etc were presented as percentages whereas quantitative measures like age, length of hospital stay were given as mean and standard deviation.

\section{Results}

A retrograde analysis of 2 years found to have 44 cases of bilateral IIAL. The mean age of the participant was $28.61 \pm 4.53$. Mode of delivery was SVD in 22(50\%) and C-section in rest of $22(50 \%)$ patients. The Mean gravidity and Parity of included patients was $2.9 \pm$ 1.02 (Range 1-5) and $2.02 \pm 0.87$ (Minimum 1, Maximum 4). The distribution of ultrasound findings is presented in Table 1

Table 1:

\begin{tabular}{ll}
\hline Ultrasound Findings & Table 1: \\
\hline Normal USG with single Baby & Frequency \\
Twin Pregnancy & $20(45.5 \%)$ \\
Polyhydrominas & $4(9.1 \%)$ \\
Placenta Preavia & $2(4.5 \%)$ \\
Placenta Accreta & $11(25 \%)$ \\
Placenta Percreta & $5(11.4 \%)$ \\
Placenta Increta & $1(2.3 \%)$ \\
\hline
\end{tabular}

The risk factors of PPH found in our study were delayed $3^{\text {rd }}$ stage of Labor , episiotomy , previous history of PPH and coagulopathy with percentage distribution as $11.36 \%(5), 9.1 \%(4), 4.5 \%$ (2) and 4 (9.1\%) respectively. Most common cause of PPH was found to be Uterine atony $(65.9 \%)$ followed by placental abnormalities $(25.9 \%)$. The relative Distribution of these risk factors and causes is shown in Table 2 .

Table 2:

\begin{tabular}{|c|c|c|c|}
\hline Risk Factors & Frequency & CAUSES OF PPH & Frequency \\
\hline Prolonged $3^{\text {rd }}$ stage of Labor & $5(11.36 \%)$ & Uterine Atony & $29(65.9 \%)$ \\
\hline Episiotomy & $4(9.1 \%)$ & Placental Abnormality & $7(15.9 \%)$ \\
\hline Previous History of PPH & $2(4.5 \%)$ & Uterine Rupture & $4(9.1 \%)$ \\
\hline & & Coagulopathy & $4(9.1 \%)$ \\
\hline
\end{tabular}

All the included patients who underwent bilateral IIAL survived. The success rate of this procedure was $100 \%$ in our setup with regard to mortality. There were $17(38.6 \%)$ patients who did not develop any post-operative complication with average hospital stay of $7.97 \pm 2.82$ days in all the patients. 10 patients got wound infection and 9 had pneumonia. 4 (9.1\%) patients developed disseminated intravascular coagulation with renal failure. All of these four patients also survived. The frequency distribution of post operative complications is given in table 3.

Table 3:

\begin{tabular}{ll}
\hline Post Operative Complications & Frequency \\
\hline No post operative Complication & $17(38.6 \%)$ \\
Wound Infection & $10(22.7 \%)$ \\
Pneumonia & $9(20.5 \%)$ \\
Paralytic ileus & $4(9.1 \%)$ \\
DIC with Acute Renal Failure & $4(9.1 \%)$ \\
\hline
\end{tabular}

\section{Discussion}

PPH needs to be managed timely and precisely since it is one of the leading emergencies in Obstetrics leading to mortality. After the failure of conservative management, refractory PPH is best managed surgically. A safe procedure is bilateral IIAL preserving the uterus from hysterectomy. We analyzed the efficacy of this procedure.

The efficacy of this procedure in the form of bleeding control was found to be $100 \%$ in our study and there was no re-opening of the abdomen. All the 44 patients survived with $100 \%$ success rate. This finding is consistent to literature. However studies with widely varied results have also been reported. [14-19]

Mode of delivery was c-section in half $(50 \%)$ of the patients and vaginal delivery in remaining half. This fact is quiet contrasting to data from a study of European country where C-section percentages were higher than our study. [18]. [19] The risk factors for PPH were also studied and Placental abnormalities and prolonged third stage of labor were found to the most common of all. This has been observed in many other studies. [3], [8], [20] We found Uterine atony to be the most common cause of PPH. This has consistently been found in literature. There exists no contrasting results in this regard.

Although all the patients survived but there were many post operative complications that were encountered. The spectrum of distribution of POC is shown below: 


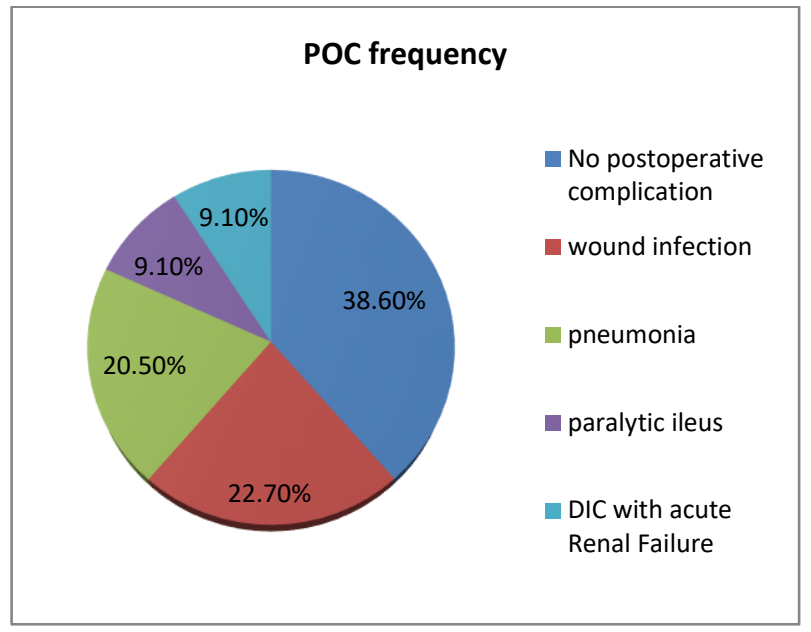

Most Common complication was wound infection (10) followed by pneumonia, paralytic ileus and DIC. Wound infection can be prevented with better care of the wound and sterile measurements during and after the surgery. However Re-do of the surgery or hysterectomy was not needed in any case. The 4 patients who developed DIC with renal failure delivered through SVD. The complications of surgery were observed in to be more pronounced in those who had SVD. [20] This may be due to lesser attention of the treating physician and attendants after SVD than C-section. So, diagnosing PPH as early as possible will give us time for conservative managements to be made at its best along with time for preparation of surgery which would reduce the complications.

Those who had C-section, the complication rate was more commonly observed among the patients with placental abnormality. This was also reported by Kaya et al. The probable explanation to the fact is extra duration of surgery required for managing placental abnormalities that lengthen surgery time and hence complication rate. [21].

Our study has shown IIAL to be an excellent procedure that not only controls bleeding but also preserves fertility. This should be preferred in cases where women is young and wants to conceive again. However There are few limitations of the study. It has small sample size; retrograde nature, single centered, operating skills dependant procedure and lack of long term follow up with regard to effect on fertility and comparison with other surgical procedures. A large, multicentre prospective study comparing different surgical techniques for bleeding control in PPH is recommended to precisely assess the efficacy of the procedure

\section{Conclusion}

Bilateral IIAL is an effective procedure to control bleeding in PPH. This is a preferred and recommended procedure especially in cases of uterine salvage where fertility needs to be preserved. However a follow-up study after this procedure to assess its fertility impairment effect if any is recommended.

\section{Declarations section}

\section{Ethics approval and consent to participate}

The study protocols and informed consent documents were approved by the Institutional Bioethics Review Committee (IBRC).

\section{Availability of data and materials}

The datasets used and/or analyzed during the study are available from the corresponding author on reasonable request.

\section{Competing interests}

The authors declare that they have no competing interests.

\section{Funding}

There is no role of any funding agency in this study.

\section{References}

[1] Sentilhes L, Merlot B, Madar H, Sztark F, Brun S, Deneux-Tharaux C. Postpartum haemorrhage: prevention and treatment. Expert review of hematology. 2016 Nov 1;9(11):1043-61. https://doi.org/10.1080/17474086.2016.1245135.

[2] World Health Organization. WHO recommendations for the prevention and treatment of postpartum haemorrhage. World Health Organization; 2012.

[3] Ford JB, Patterson JA, Seeho SK, Roberts CL. Trends and outcomes of postpartum haemorrhage, 2003-2011. BMC pregnancy and childbirth. 2015 Dec;15(1):1-0. https://doi.org/10.1186/s12884-015-0788-5. 
[4] Lutomski JE, Byrne BM, Devane D, Greene RA. Increasing trends in atonic postpartum haemorrhage in Ireland: an 11-year population-based cohort study. BJOG: An International Journal of Obstetrics \& Gynaecology. 2012 Feb;119(3):306-14. https://doi.org/10.1111/j.14710528.2011.03198.x.

[5] Chandraharan E, Krishna A. Diagnosis and management of postpartum haemorrhage. Bmj. 2017 Sep 27;358. https://doi.org/10.1136/bmj.j3875.

[6] Mousa HA, Blum J, Abou El Senoun G, Shakur H, Alfirevic Z. Treatment for primary postpartum haemorrhage. Cochrane database of systematic reviews. 2014(2). https://doi.org/10.1002/14651858.CD003249.pub3.

[7] Wu S, Kocherginsky M, Hibbard JU. Abnormal placentation: twenty-year analysis. American journal of obstetrics and gynecology. 2005 May 1;192(5):1458-61. https://doi.org/10.1016/j.ajog.2004.12.074

[8] Calvert C, Thomas SL, Ronsmans C, Wagner KS, Adler AJ, Filippi V. Identifying regional variation in the prevalence of postpartum haemorrhage: a systematic review and meta-analysis. PloS one. 2012 Jul 23;7(7):e41114. https://doi.org/10.1371/journal.pone.0041114

[9] Briley A, Seed PT, Tydeman G, Ballard H, Waterstone M, Sandall J, Poston L, Tribe RM, Bewley S. Reporting errors, incidence and risk factors for postpartum haemorrhage and progression to severe PPH: a prospective observational study. BJOG: An International Journal of Obstetrics \& Gynaecology. 2014 Jun;121(7):876-88. https://doi.org/10.1111/1471-0528.12588.

[10] Davey MA, Flood M, Pollock W, Cullinane F, McDonald S. Risk factors for severe postpartum haemorrhage: A population-based retrospective cohort study. Australian and New Zealand Journal of Obstetrics and Gynaecology. 2020 Aug;60(4):522-32. https://doi.org/10.1111/ajo.13099.

[11] Reyal F, Deffarges J, Luton D, Blot P, Oury JF, Sibony O. Severe post-partum hemorrhage: descriptive study at the Robert-Debre Hospital maternity ward. Journal de gynecologie, obstetrique et biologie de la reproduction. 2002 Jun 1;31(4):358-64.

[12] Weeks AD. Recent advances in understanding the enduring nand deadly complication of postpartum haemorrhage Preface. Best Practice \& Research Clinical Obstetrics \& Gynaecology. 2019;61:1-2. https://doi.org/10.1016/j.bpobgyn.2019.08.005.

[13] Rani PR, Begum J. Recent advances in the management of major postpartum haemorrhage-a review. Journal of clinical and diagnostic research: JCDR. 2017 Feb;11(2):QE01. https://doi.org/10.7860/JCDR/2017/22659.9463.

[14] Joshi VM, Otiv SR, Majumder R, Nikam YA, Shrivastava M. Internal iliac artery ligation for arresting postpartum haemorrhage. BJOG: An International Journal of Obstetrics \& Gynaecology. 2007 Mar;114(3):356-61. https://doi.org/10.1111/j.1471-0528.2006.01235.x.

[15] Iwata A, Murayama Y, Itakura A, Baba K, Seki H, Takeda S. Limitations of internal iliac artery ligation for the reduction of intraoperative hemorrhage during cesarean hysterectomy in cases of placenta previa accreta. Journal of Obstetrics and Gynaecology Research. 2010 Apr;36(2):254-9. https://doi.org/10.1111/j.1447-0756.2009.01157.x.

[16] Madhubala M. Bilateral Internal Iliac Artery Ligation, a Rational Choice of Surgery in Placenta Previa, a Hospital-Based Retrospective Study on the Prevention of Hysterectomy and Control of Postpartum Hemorrhage. The Journal of Obstetrics and Gynecology of India. 2019 Dec;69(6):53540. https://doi.org/10.1007/s13224-019-01258-8.

[17] Camuzcuoglu H, Toy H, Vural M, Yildiz F, Aydın H. Internal iliac artery ligation for severe postpartum hemorrhage and severe hemorrhage after postpartum hysterectomy. Journal of Obstetrics and Gynaecology Research. 2010 Jun; 36(3):538-43. https://doi.org/10.1111/j.14470756.2010.01198.x.

[18] Evsen MS, Sak ME, Soydinc HE, Basaranoglu S, Bakir C, Sak S, Gul T. Internal iliac artery ligation for severe postpartum hemorrhage. Ginekologia polska. 2012; 83(9).

[19] Simsek Y, Yilmaz E, Çelik E, Karaer IT, Turhan U, Celik O. Efficacy of internal iliac artery ligation on the management of postpartum hemorrhage and its impact on the ovarian reserve. J Turk soc obstet Gynecol. 2012;9(3):153-8. https://doi.org/10.5505/tjod.2012.26576.

[20] Kaya B, Damarer Z, Daglar K, Unal O, Soliman A, Guralp O. Is there yet a role for internal iliac artery ligation in obstetric hemorrhage with the current gain in popularity of other uterus sparing techniques?. The journal of maternal-fetal \& neonatal medicine. 2017 Jun 3;30(11):1325-32. https://doi.org/10.1080/14767058.2016.1212333.

[21] Kaya B, Usluogullari B, Yurttutan N, Sahan MH, Güralp O, Malik E. Does ligation of internal iliac artery for postpartum hemorrhage affect clitoral artery blood flow and postpartum sexual functions?. European journal of obstetrics \& gynecology and reproductive biology. 2017 Dec 1;219:124-8. https://doi.org/10.1016/j.ejogrb.2017.10.029. 